Peer-Reviewed Journal

\title{
Critical Review of Shakespearean Language: Linguistic Perspectives
}

\author{
Dr. Lina Fathi Sidig Sidgi
}

\author{
Al-Turath University College, Baghdad, Iraq
}

Received: 07 Nov 2021; Received in revised form: 09 Dec 2021; Accepted: 15 Dec 2021; Available online: 20 Dec 2021

C2021 The Author(s). Published by Infogain Publication. This is an open access article under the CC BY license

(https://creativecommons.org/licenses/by/4.0/).

\begin{abstract}
This paper aims at analyzing the grammatical and linguistic issues of Shakespearean English. The various techniques of this paper are driven from main fields of English language such as linguistics, pragmatics, and discourse analysis. Moreover, this paper sheds light on the self-presentation of Shakespearean English speakers in language and their own ways in communicating with others. Furthermore, the argument in this paper shows that the grammatical rules that control the linguistic usage of the Shakespearean language provide a lot of information about interaction and interpersonal relationships. Therefore, this paper also focuses on the great influence of Shakespearean English on modern English language through many Shakespearean idioms and new words that are used even in the present times as well as the notable influence of Shakespearean English on today's English pronunciation, grammar, and vocabulary.
\end{abstract}

Keywords - Shakespearean English, modern English, grammar, pragmatics, and discourse analysis.

\section{INTRODUCTION}

This study analyzes the linguistic and grammatical details of Shakespearean English, which have been undertheorized by language scholars. The tools of research in this study are derived from three major fields, which are discourse analysis, pragmatics, and linguistics. Using these tools, the researcher traces the self-presentation of Shakespearean English speakers in language and their position in relation to others. The study is grounded in a collection of William Shakespeare's writings in which the idea of self-positioning is rather fraught.

The study argues that the grammar rules that control the linguistic usage of the Shakespearean language tell a lot about interpersonal relationships and interaction. Further, the researcher holds that the tiny details of linguistic interactions are key hints for how language users perceive themselves, their environments, and interlocutors. Such details include easily ignored words such as pronouns (you and thou) and modal verbs (will and shall) as well as deictic markers like now, this, and I(Engle, 1993). The study gives as much attention to such minute details as other prominent moments of linguistic encounter to shed light on how language demonstrates interpersonal connections, self-perception, and self-presentation.

Engle (1993) stated that it is impossible to look at any work of Shakespeare without talking about language. Audiences can never help but notice the discrepancy in language whenever they watch a play or read a book written in the Shakespearean language. All readers bring their own language to the theatre or the book, and that creates a problem when dealing with early modern English, which gives a false sense of apparent obviousness and ease at the first encounter. Readers interact with authors of texts through reading. Since there are four centuries of linguistic change separating today's readers from the speakers of Shakespearean English, it is necessary to critically explore connections between Shakespearean English and Modern English.

Some of the limitations that modern readers encounter when dealing with Shakespearean language may be apparent sometimes, like when one meets a word and has no idea what it means. But the difficulties are sometimes 
hidden, like when one meets a word that seems familiar and thinks they know its meaning. Such words are called 'false friends,' and are among the main causes of error for second language beginners. When readers see 'aimer' in French for the first time, they think it means 'aim' when it actually means 'love.' They are also a big source of error in understanding Shakespeare's language. In As You Like It, Le Beau says that Duke Frederick is 'humorous' (Shakespeare, 2011, 1.2.233) to mean that he is temperamental. 'Humorous' as used in current modern English does not make sense in the context of Le Beau's statement considering how wickedly he was treating Orlando.

The difference between Modern English users' instincts about language and Shakespeare's cut across all areas of language (Gotti, 2002). Both grammar and pronunciation have familiar words that mean different things. This discrepancy is also evident in how characters address each other. All these are important considerations in understanding Shakespearean language. One way to understand the Shakespearean language is to identify language problems in texts or plays on a case to case basis, through the help of editor's textual notes. This method has been used for a long time, but it has many limitations in creating awareness of early modern English (Gotti, 2002). One limitation is that editions leave out some linguistic points because they lack enough space, and others take thematic approaches that allow them to give very limited explanations. Another limitation is that it is difficult to build up awareness of normal aspects of language in Shakespearean English because of the huge time periods between the $16^{\text {th }}$-century society and today's society.

The other way is to systematically look at the differences like in learning a foreign language. One can try to master the norms of Early Modern English usage by giving attention to Shakespearian language from the early stages of their learning. This approach is important because it offers the only way to get to the root of Shakespeare's linguistic creativity. Like modern-day poets, a reader of Shakespearean English must understand the rules of its grammar before he tries to break or bend them. This rule applies to discourse, vocabulary, and pronunciation. It is also important in understanding the changes that characterize linguistic creativity. It is necessary to first appreciate the language of Shakespeare's time to be able to appreciate how he manipulated it.

\section{LITERATURE REVIEW}

Since time immemorial, socio-cultural and historical events have impacted language at different extents, favoring and promoting transformations at various levels. The Renaissance movement of the $15^{\text {th }}$ century had extensive consequences in all areas of intellectual work throughout Europe.

The ferment was in England as well. The Renaissance created a new contact with the early classical culture, which motivated intellectuals to seek out new knowledge from ancient Greek and Latin texts (De Grazia, 2001). Meanwhile, William Caxton introduced printing into England towards the end of the fifteenth century, making it possible for many people in the territory to access books (Kastovsky\&Mettinger, 2011). New modes of communications then came up, connecting different parts of the world, and increasing international trade. With all these factors in place, several aspects of life changed. They influenced all features of communication, especially language. Historical accounts of the English language suggest that the Renaissance came with the fast expansion of the English lexicon (Kastovsky\&Mettinger, 2011). English vocabulary encompassed new words from oversees and classical origin, although Purists dispute this fact (Baugh \&Cable, 2002).

The political situation in England in the $16^{\text {th }}$ century was equally important to the development of Shakespearean language. According to De Grazia (2001), the period was marked with the powerful and stable reign of Queen Elizabeth I (1558-1603). Under her leadership, England prospered and began to appreciate many social transformations, like establishing huge commercial theatres where artists could perform for the public. Shakespeare lived in this age and he used his sensitivity, skills, and cleverness to exploit the language transformations (Cavell, 2003). Although the language used in Shakespeare's poems and plays is perceived as elaborate and complex, it forms a rich collection of linguistic phenomena for English language analysis and research.

Readers of Shakespeare's works can be involved in a number of implicit choices because the author uses language to achieve specific stylistic effects meant to persuade the audience (Cheney et al., 2004). All the works of Shakespeare employ the resources of rhetoric, both as a tool to try out new things with language and a method of composition.

Although the effectiveness of communication depends on the organization as well as the disposition of the components in a discourse, the peculiarity and originality of Shakespearean language encompasses more than just rhetoric and goes beyond the surface of discourse. Some elements can occur at higher levels, like syntax. The way Shakespeare experimentally employs alternate loosening structures in his work shows the intention to avoid monotony, and most importantly, cognizance of speech 
structure (Cheney et al., 2004). Features related to grammar occur in the various use of negation - nor and neither and changes between the usage of verb endings -es and -eth. Both of these aspects offer important diachronic data for researchers.

Shakespeare wrote more than 10 lays in all genres history, tragedy, and comedy as well as several sonnets, and two long narrative poems entitled The Rape of Lucrece and Venus. All of Shakespeare's works are linguistically unique and demonstrate his increasing and consistent need to experiment with the lexicon and other language resources (Grazia\& Wells, 2010). The lexicon of a given language is a product of many aspects of the everyday life of its speakers and reflects their history. English lexicon originates from several languages; it captures the core vocabulary and basic roots of Anglo-Saxon (450 - 1150), learned elements borrowed from Greek and Latin writings (1500), romance features originating from the classical and the Norman Conquest (1066) (Grazia\& Wells, 2010). The reawakening of Greek and Latin literature triggered the urge to transfer important Greek and Latin roots in English to the extent of enriching the English lexicon. The period saw about 10,000 new lexemes added to English (Baugh and Cable, 2002).

A critical examination of Shakespearean language explains certain methods used in creating new words using Latin roots and Latin morphemes combined with Anglo-Saxon bases e.g. homeless. Bryan A. Garner (1987) conducted a study, in which he noted down more than 600 Latinate neologisms in the works of Shakespeare (Lenker\&Meurman-Solin, 2007). Garner list only included new words and left out old ones that Shakespeare used creatively with new meanings or assigned to different parts of speech. All the words in the count have Latin bases. Some are hybrid, combining Latinate suffixes or prefixes with Anglo-Saxon roots while others simply contain one or more bound Latinate morphemes.

Besides, Garner omitted -ly adverbs, participles, and compound words developed from verbs that are already in use. The collection also left out ignorant pronunciations, malapropisms, comic inventions, as well as Spanish and Italian borrowings. Lenker and Meurman-Solin (2007) further observe that many neologisms in Shakespearean English were wrongly-formed words through violation of Latin word formation rules. As a result, at least 30 per cent of Shakespearean neologisms have not stuck permanently in Modern English. Nonetheless, Shakespeare's remarkably manipulated language, playing with words, in particular, to achieve desired literary effects in specific contexts.

\section{METHODS}

The research collected Shakespeare's narrative poems, plays, and sonnets in digital form and organized them in chronological order using information published in Complete Oxford Shakespeare(Schoenfeldt, 2010). Using the Wordsmith, the researcher processed the collection of Shakespeare's works and noted the total number of words in each of them.

Since the collection of Shakespearean writings comprised a combination of works from different genres, for purposes of this research, they were categorized into folios on the basis of publication era. The first folio comprised of plays that were first published before 1663 . They included all the three divisions of Shakespeare's works - tragedies, histories, and comedies. The second folio comprised of two plays, Prince of Tyre and Pericles, both of which were published after 1663 (Schoenfeldt, 2010).

Further, the computer programme, WordCruncher was used to investigate the collection of Shakesperean writings. The tool explores electronic texts that have been indexed and bookmarked. Using the WordCruncher, the researcher was able to retrieve information of different kinds, looking beyond collocations and word frequency. The researcher was able to retrieve characters as well as information on any line, scene, act, or play.

\section{RESULTS AND DISCUSSION}

\subsection{How Shakespearean English Relates to Modern English}

It is much easier to learn the Shakespearean language than a foreign language because of the continuities that exist between Modern English and Early Modern English. Most of the differences in Shakespearean English do not pose any serious linguistic problem for modern English speakers.

\section{GRATIANO}

We have not made good preparation.

\section{SALARINO}

We have not spoke us yet of torchbearers.

\section{SALANIO}

'Tis vile, unless it may be quaintly order'd, And better in my mind not undertook.

\section{LORENZO}

'Tis now but four o'clock: we have two hours

To furnish us.(Shakespeare, 1969, 2002, 2.4.4-9)

The usage of 'tis', which is a recurrent feature in this excerpt, still resonates with Modern English. Although it seems strange in writing it is commonly used in a 
colloquial speech today. It is just like words, such as 'thy', 'thou', and 'thee', all of which can still be found in some regional and religious expressions. 'Spoke' as used here is equivalent to 'spoken'in modern Standard English. The two are very close forms of the same verbs, and they both still exist in different dialects today. Therefore, the usage of 'spoke' here cannot be a problem. Similarly, the phrasings, 'have not spoke us' and 'furnish us'sound quite old-fashioned but can easily interpret their meanings in the context of the text. They are also common in some regional dialects. Perhaps the only phrase that may be problematic for Modern English speakers is in my mind not undertook. Overall, a modern intuition would not require much special help to understand this conversation.

Sometimes, the difficulty may be readily evident in some Early Modern English texts. In the following extract, for example, Portia just told Nesissa that they should disguise themselves as men. To her surprise, Nerissa did not understand what she was talking about as she thinks Portia wants them to turn to men. Each line communicates an almost obvious meaning, except line two and line six. In the second line, Portia tells Nerissa that if she had a dirty mind, she would think she meant giving themselves to men sexually. In the sixth line, she means that they have to cover 20 miles.

Fie, what a question's that

If thou wert near a lewd interpreter! But come, I'll tell thee all my whole device

When I am in my coach, which stays for us

At the park gate; and therefore haste away,

For we must measure twenty miles today. (Shakespeare 2002, 3.4.82-87)

Since most of the lines have words or phrases that need some clarification, they create temporary uncertainty. Nonetheless, words like lewd, device, haste, and coach are still used in modern English, which makes their meaning rather plain (Blake, 2004). People who are not familiar with such less commonly used words may find Shakespearean English inaccessible and unintelligible. But one needs to read the entire speech without focusing on the difficult parts because this English variety has some familiar bits that help in constructing the right meaning. Most of the time, it is possible to tell what an author intends to communicate even if there are a few unfamiliar words in a statement.

Meeting the difficult words and phrases used to express complex ideas in Elizabethan English is what reinforces the impression that it is a foreign language. Moreover, the fact that the educational practice has greatly changed since the time of Shakespeare does not help the situation either. Roman and Greek mythology have become less familiar today and make many extended pieces of imagery used in the Shakespearean language alien to modern students. However, this problem is related to a lack of general knowledge of classical times and cultures rather than linguistic or speech difficulty. For example, when Salarino says:

Now, by two-headed Janus,

Nature hath framed strange fellows in her time... (Shakespeare, 1969, 1.1.52-53)

This statement does not have any linguistic problem, but it does not make sense for anyone who does not know who the Janus is. Janus is a god of duality that exists in Roman mythology. This matter has nothing to do with language change.

Notably, some parts of expressions in Shakespearean language are in foreign languages, such as Italian, Spanish, Latin, and French, and they involve the same educational points. In Early Modern English days, most English speakers learned Latin and French in school. Therefore, they would not have problems with passages with a lot of French as in the scenes in Henry $V$.

There is a third type of difficulty with Shakespearean English that lies in between the two extremes. It occurs in texts with two levels of complexity, which are easy to understand at one level and difficulty at another. For example, in King Lear, a lot of the vocabulary that Kent uses to criticize Oswald is so unfamiliar that someone who is new to Shakespeare's language can only get a rough idea. Nonetheless, anyone should be able to tell that the statement is castigating or insulting.
A knave; a rascal; an eater of broken meats; a base, proud, shallow, beggarly, three-suited, hundred-pound, filthy worsted-stocking knave... (Shakespeare, 2002, 2.2.13-15)

New language users have no problem catching a drift as it commonly happens with abusive language. At the individual interaction level, it is easy to notice that these phrases are somehow demeaning, and using many of them creates a cumulative effect, despite including a lot of unintelligible vocabulary. Watching a stage performance of this speech will certainly bring out this effect.

Learning a language does not begin with trying to master its complex passages first. This principle is not only true for a foreign language but also for Shakespearean English. Understanding Early Modern English requires systematic unravelling the different types of difficulty found in it. The incomprehensible aspects should be left to a later time, to 
enable newcomers to deal with the commonly occurring issues first.

\subsection{New and Old Aspects of Shakespearean English}

It is important to note that the Shakespearean period is linguistically heterogeneous, just like all other language periods. In today's Modern English, some words are new, others are old, and some are current. The older usages of language are referred to as 'archaisms' or 'obsolete words' while the current usages are referred to as 'neologisms' or 'coinages'. New usage of language is easy to spot because its novelty makes it stand out and attract a certain level of comment. People rarely comment on language usages that are becoming obsolete, making them disappear silently.

Early Modern English was marked with amazingly dynamic changes. The outcome of the Renaissance was impacting the language, causing great dismay among users, not knowing how to react to the lots of new words being developed from Greek and Latin. Language usage was characterized by a lot of self-consciousness at the period, which stands out for its lexical experimentation and inventiveness, of which Shakespeare was a major contributor.

Although neologisms of the past and archaisms always exist, it is difficult to develop their awareness in the modern language. Shakespeare used several of these aspects in Henry IV and Pericles, including 'hight'(called) and 'iwis' ('indeed'). These works also have older verb forms like $y$-clad for clothed and 'speken' for speak. Shakespearean English speakers would have considered such words as archaic or old-fashioned. Other examples are 'eke'('also'), 'ght' ('person'), and 'eyne' ('eyes'). Most of these words are borrowed from Medieval or Middle English.

For the benefit of neologisms, characters in Shakespeare's plays highlight instances of new usages and words. For example, in Love's Labour's Lost, Biron refers to the Spanish court visitor as 'A man of fire-new words' (Shakespeare, 2020, 1.1.176). Arnado also uses language to entrench the distinction between the classes. That is the same way Mercutio views Tybalt in Romeo and Juliet

The pox of such antic, lisping, affecting phantasms, these new tuners of accent! 'By Jesu... a very good blade, a very tall man, a very good whore'...(Shakespeare, 2000,2.3.25-7)

It is evident from this statement that Mercutio does not like using very as an adverb intensifying a positive adjective. This was a common linguistic trend in the Elizabethan English period. Another fashionable word that appeared in the same period was accommodated, which Bardolph uses in Henry $I V$, as well as many new senses of humour, which are used repeatedly in TheMerry Wives of Windsor. Shakespeare had a new style that normalized 'hard words' as can be seen from the malapropisms in the speech of ordinary characters like Dogberry, Mistress Quickly, and clowns like Lancelot. In The Merchant of Venice,Lancelot tells Shylock, 'I beseech you, sir, go: my young master doth expect your reproach'(Shakespeare, 1969, 2.5.20-21). It appears that Shakespearean language did not have a pompous speech from the way many of the characters make fun of linguistic affectation. In The Merchant of Venice, after Gratiano tries to cheer up Antonio, he turns to Bassanio:

\section{ANTONIO}

Is that any thing now?

\section{BASSANIO}

Gratiano speaks an infinite deal of nothing, more than any man in all Venice... (Shakespeare, 1969, 1. 1.115-117)

\subsection{Varieties of Shakespearean English}

Shakespeare paints a vivid picture of the kind of social situations that characterized the Elizabethan England. However, it has never been emphasized enough that each of the situations that Shakespeare portrays is distinctive linguistically. There was courtly, religious, and legal English;just like there is broadcasting, advertising, and scientific English today. Besides neologisms and archaisms, easy words, and hard words, there is language representing regional origins, social class, intimacy, and formality at various degrees. Thus, the plays have many of the Early Modern English varieties.

Modern English readers often do not go beyond the superficial observations by modern commentators to appreciate the whole picture of the stylistic variation in speeches of the past, because they fully rely on the written language. But they can get some clues from the way the characters are portrayed in the plays. For example, when Evans uses the phrase, 'how melancholies I am' in The Merry Wives of Windsor, he is not speaking Early Modern English but humorous Welsh dialect. Fluellen also made such utterances in Henry $V$.

The spellings 'falorous' instead of 'valorous' and 'pless'instead of 'bless'show distinctions in pronunciation. Shakespeare also uses the phrase 'look you', which is famously associated with Welsh. However, since its usage has become less common in Welsh speech today, it is not clear whether the usage of the phrase in Shakespeare represented a greater reality that time than it does now. The persistent usage of wrong grammar among these speakers represents a significant element of pastiche. The two plays also have clues of Scottish and Irish as evident 
in the speech of Macmorris and Jamy respectively. Katherine and Caius had French accents, while in King Lear, Edgar uses West Country speech.

Nonetheless, Shakespeare is not as keen on representing regional variation as social variation, particularly class differences. While it is possible for people to hide their faces, they can never hide their voices. In As You Like It, Orlando meets Rosalind, who is disguised, and takes note of her speech, "Your accent is something finer than you could purchase in so removed a dwelling"(Shakespeare, 2011, 3.2.310-11). Similarly, in King Lear, Edmund recognizes Edgar's speech when he is disguised, 'thy tongue some say of breeding breathes' (Shakespeare, 2002, 5.3.142).

The same effect is also seen in vocabulary and grammar. In Henry IV, Prince Hal tells Poins, 'I am so good a proficient in one-quarter of an hour that I can drink with any tinker in his own language during my life' (Shakespeare, 1998, 2.5.15-17). Like Hotspur says, the upper classes also hand their own speech, dominated by words 'holiday and lady terms' (Shakespeare, 1998, 1.3.45). Most of the terms used to mark class differences are found in what people tell each other - in their oaths, insults, endearment terms, and titles. It is crucial to take note of the use of forms such as 'gentle', 'master', 'wech', and 'sirrah'. Such terms point out relationships and personal temperaments (Wortham, 2003). For example, in Henry IV, Hotspur demonstrates differences in swearing habits.

LADY PERCY: Not mine, in good sooth.

HOTSPUR: Not yours, in good sooth! Heart, you swear like a comfit-maker's wife

'Not you, in good sooth!' and 'As true as I live' and 'As God shall mend me!' and 'As sure as day!' (Shakespeare, 1998, 3.1.241-6)

While Lady Percy only uses word sooth, Hotspur prefers to swear using many words in addition to sooth.

\subsection{Manipulation of Standard Language Rules in Shakespearean English}

Shakespeare shares an intimate relationship with Early Modern English. One needs to comprehend the linguistic norms of the Shakespearean age to correctly appreciate how he departs from these standards. At the same time, little is known about the language norms of this age besides what can be seen from Shakespeare's plays themselves. Therefore, it is necessary to always on the relationship between the two dimensions. Early Modern English should not be studied separately from Shakespearean English. Instead, Shakespeare should be used as a medium of studying Early Modern English and the two should be looked at alongside each other.

It is possible to understand the nature of the rules of a language by examining how a writer breaks and bends (manipulates) them. An important question to ask at all times is why authors manipulate linguistic rules. A critical analysis of language needs to go further than just 'featurespotting'. It is not enough to be able to recognize the usage of neologism in a given line. It is necessary to get to the next step, which is examining the purpose of the neologism. It is at this level that a Modern English reader may get to think about an issue the way Shakespeare himself may have looked at it. Why did he manipulate that linguistic norm the way he did? What effect would he have created with a different approach? The important question is whether it is always necessary to use a linguistic form or not.

\subsection{Manipulation of Grammar Rules}

\subsubsection{Pronouns}

Both attitudinal and social differences are so crucial that they determine the choice of some frequently used pronouns in a language such as 'you' and 'thou'. In old varieties of English, 'thou' was used to show singular, and you denoted plural. Towards the 14th century, people began to use you as singular to politely address others (Freedman, 2017). This change was probably influenced by French speech, where 'vous' is used as a polite form of the singular 'tu'. Hence, like French, English had 'thou' and 'you' as possible singular forms, giving speakers a choice. The form 'you' was commonly used by inferiors addressing superiors, like servants talking to masters or children talking to parents (Freedman, 2017). The superiors used 'thou' in return. But the use of 'thou' was also common in instances where people desired greater intimacy, like when talking to God. It was also normal to use 'thou' in conversations between the lower classes. It was a rule that upper classes address each other with 'you', even if they were close relatives.

Therefore, it was common for people to shift from 'you' to 'thou' and vice versa when people talked to each other, and it always meant something (Eggins, 2004). The change marked a difference in mood and emotion. The new meaning conveyed could be anything from playfulness, to sarcasm, to power distance, to anger, to affection. It could be considered insulting to call someone 'thou' as Andrew Aguecheek does to his enemy in (Shakespeare, 2011, 3.2.37-8). The changing relationships and attitudes of characters could, therefore, be seen in how they shifted between the two pronouns. There is a good illustration of such usage of the two pronouns in The Merchant of Venice where Gobbo, who is blind, first addresses a man with 
'you' but when he realizes that it is Lancelot his son, he uses 'thou' to show familiarity.

GOBBO. I cannot think you are my son.

LANCELOT. I know not what I shall think of that, but I am Lancelot, the Jew's man, and I am sure Margery your wife is my mother.

GOBBO. Her name is Margery indeed! I'll be sworn if thou be Lancelot, thou art mine own flesh and blood.

(Shakespeare, 1969, 2.2.81-86)

Similarly, Wortham (2003) observed that in the first scene of King Lear, the king addresses his daughter, Goneril with 'thou' as they use 'you' to him.

GONERIL: Sir, I love you more than words can wield the matter.

LEAR: Of all these bounds, even from this line to this... We make thee lady... (Shakespeare, 2002, 1.1.53-59)

However, in one instance he addresses his favourite daughter Cordelia with 'you' in what critics have suggested as a show of affection and special relationship. (Shakespeare, 2002, 1.1.104-8)

\subsubsection{Modal Verbs}

Shakespeare uses the two modal verbs, shall and will in new ways to communicate powerful instincts and encode their speaker's perspective. However, the usage of these two words in Shakespearean language demonstrates a complexity that can be attributed to linguistic history. According to Cummings (2002), will and shall are among the most complex words in English. Language scholars have cited many difficulties in classifying the two words because Shakespeare uses both of them as verbs in their own right and as auxiliary verbs. Despite the many attempts to categorize their usage and meanings, it has not been easy to reach consensus.

In spite of the confusion surrounding the two words, it is important to briefly paint a picture of the typical relationship between will and shall in this discussion. In present-day language, the two are generally considered to offer distinct, yet analogous means by which speakers articulate and conceptualize the future. It has been argued that the choice whether to use will or shall lies in other more complex considerations such as relative certainty and necessity (Eggins, 2004). While the two are thought to have the same core meaning, they are formal variants whose usage depends on the context.

However, in Shakespearean language, will and shall were significantly less interchangeable (Cummings, 2002). Whereas will could be used to signify two things - desire and future expectation - depending on the context, shall specifically communicate less certain future expectations. Will and shall had much more resonant semantic differences in Shakespeare's time. Hence, the author's modal choices provoke distinct thoughts. Craig (2000) explains that while the two modal verbs were originally used as main lexical verbs in Early Modern English, their grammatical position began to change from being primary verbs to auxiliary verbs towards the end of the 16th century.

\subsubsection{Invention of Vocabulary}

It is impossible to make a pragmatic analysis of language choice and usage without giving attention to vocabulary. However, it is crucial to note that an author does not have a choice with all words. Many unfamiliar vocabularies of Shakespearean English only exist as a reflection of historical culture, like the words used for sailing ships, weapons, body-armour, and clothing. Examples of such vocabularies include 'topgallant', 'maintop', 'pike', 'halberd', 'gauntlet', 'casque', 'hose', and 'doublet'. They are words that came to mind automatically when Shakespeare had decided to discuss a certain subject area. Modern English speakers can only understand such words if they take the time to learn the Elizabethan culture. But many of the words considered to be distinctively Shakespearean are different because they involve choosing between at least two words.

In the prologue for Henry $V$, Shakespeare uses two distinctive vocabularies in the first sentence - 'cockpit' and 'vasty'. The Oxford English Dictionary assigns the first use of these two words to Shakespeare, who used 'cockpit' to mean 'theatre pit' and 'vasty' to mean 'vast'. While 'cockpit' already existed in the English language, albeit with a different meaning, 'vasty' was totally new (Dobson, 2001). It is considered a creation of Shakespeare because it is similar to words like 'brisky' and 'plumpy' which were constructed in other Shakespeare's plays.

One then wonders why Shakespeare had to create a new word in this case because 'he could use 'vast' which already existed. Indeed, the author had used it in his earlier play, Romeo and Juliet. The most probable answer is that Shakespeare sought to create an extra syllable, which was necessary to make the word fit into the poetic rhythm of the line. All the lines in the speech had ten regular syllables. Therefore, if he had written 'vast' instead of 'vasty, he would have broken the steady progression.

There were other words to choose from, such as 'great', 'huge', 'large', 'enormous', and 'immense.' However, none of them dramatically captures the scene painted in the chorus like 'vasty' because they do not suit the rhythm of the line. The first record of the word vastly is traced to 
1575 (Boehrer, 2005). Hence, it sufficiently unfamiliar to add a poetic appeal to the chorus. Suffix ' $-\mathrm{y}$ ' is often used to form adjectives, and it solved the musical problem in this case in an attractive and well-acceptable way. Boehrer (2005) further notes that in the Shakespearean era, it was pretty common for people to create new words, and '-ly' had been used in this manner with other words.

\section{CONCLUSION}

Shakespearean English has some notable influence on today's English language. Shakespeare left a linguistic legacy, having coined many new words, of which some like 'courtship' and 'assassination' have remained in English to this day. There is evidence that he is also credited for creating idioms like 'cold comfort', and 'salad days.' However, Shakespeare's coinages do not add up to a very large number. No study has been able to come up with a precise count of English words and phrases that Shakespeare invented. But Shakespearean vocabulary that exists in today's modern language adds up to mere hundreds. Besides only a few dozens of the idioms he invented are still popular today. Therefore, it appears that Shakespeare is not responsible for as many modern English words as he is thought to.

Nonetheless, it is not enough to only count words when assessing Shakespeare's language, because of the need to examine his influence on other areas of language, such as pronunciation, and grammar, and how each of them creatively relates with vocabulary. Indeed, this study does not hold the assumption that quantity can be used signify quality. The key point of contact between Shakespearean English and today's modern English is not in the number of words shared but the way the words were used. Shakespearean English demonstrates that it is possible to not only explore but also exploit language resources in new ways. How Shakespeare uses language to serve poetic imagination further displays the variety and range of Elizabethan English. From the writings of Shakespeare, it is not difficult to see how to employ language in conveying the desired effects. More than anything else, Shakespeare is proof that one can dare to do anything with language. Shakespearean English offers an object-lesson on breaking and ending of language rules.

\section{REFERENCES}

[1] Baugh, A. C., \& Cable, T. (2002). A History of the English Language. Prentice Hall.

[2] Blake, N. (2004). Shakespeare's non-standard English: A dictionary of his informal language. A\&C Black.

[3] Boehrer, B. (2005). The Privy and Its Double: Scatology and Satire in Shakespeare's Theatre. A Companion to Shakespeare's Works: The Poems, Problem Comedies, Late Plays, 69-88.
[4] Cavell, S. (2003). Disowning knowledge: In seven plays of Shakespeare. Cambridge University Press.

[5] Cheney, P., Cheney, P. G., \& Patrick, C. (2004). Shakespeare, national poet-playwright. Cambridge University Press.

[6] Craig, H. (2000). Grammatical Modality in English Plays from the 1580s to the 1640s. English Literary Renaissance, 30(1), $32-54$.

[7] Cummings, B. (2002). The literary culture of the Reformation : Grammar and grace: Grammar and grace. OUP Oxford.

[8] De Grazia, E. (2001). The Cambridge Companion to Shakespeare. Cambridge University Press.

[9] Dobson, M. (2001).Shakespeare performances in England. Shakespeare Survey, 54, 246-246.

[10] Eggins, S. (2004). Introduction to systemic functional linguistics (2nd ed.). A\&C Black.

[11] Engle, L. (1993). Shakespearean pragmatism: Market of his time. University of Chicago Press.

[12] Freedman, P. (2017). Power and Passion in Shakespeare's Pronouns: Interrogating'you'and'thou'. Routledge.

[13] Gotti, M. (2002). Pragmatic uses of SHALL future constructions in Early Modern English. Studies in the History of the English Language, 301324. https://doi.org/10.1515/9783110197143.3.301

[14] Grazia, M. D., \& Wells, S. (2010). The new Cambridge companion to Shakespeare. Cambridge University Press.

[15] Karremann, I. (2015). undefined. Cambridge University Press.

[16] Kastovsky, D., \& Mettinger, A. (Eds.). (2011). The history of English in a social context: A contribution to historical sociolinguistics (Vol. 129). Walter de Gruyter.

[17] Lenker, U., \& Meurman-Solin, A. (2007). Connectives in the history of English. John Benjamins Publishing.

[18] Schoenfeldt, M. (2010). The Cambridge introduction to Shakespeare's poetry. Cambridge University Press.

[19] Shakespeare, W. (1998). Henry IV. Oxford University Press, USA. (Original work published 1598)

[20] Shakespeare, W. (2002). The complete sonnets and poems. Oxford University Press on Demand.7

[21] Shakespeare, W. (1969). The Merchant of Venice. (Original work published 1597)

[22] Shakespeare, W. (2000). Romeo and Juliet. Wordsworth Editions.(Original work published 1595)

[23] Shakespeare, W. (2002). King Lear. Oxford University Press, USA. (Original work published 1608)

[24] Shakespeare, W. (2011). As You Like It. Simon \& Schuster.(Original work published 1600)

[25] Shakespeare, W. (2011). Twelfth Night. Simon \& Schuster. (Original work published 1602)

[26] Shakespeare, W. (2020). Love's Labour's Lost. (Original work published 1595)

[27] Wortham, C. J. (2003). Literature, mapping and the politics of space in early modern Britain. Edited by Andrew Gordon and Bernhard Klein. Cambridge: Cambridge University press, 2001; pp. xiii. Theatre Survey, 44(01), 163164. https://doi.org/10.1017/s0040557403460079 